\title{
Cost-effectiveness Analysis of Golimumab in the Treatment of Non-Radiographic Axial Spondyloarthritis in Scotland
}

\author{
Rebekah H. Borse · Sumesh Kachroo - Chloe Brown · \\ Eilish McCann · Ralph P. Insinga
}

Received: January 26, 2018 / Published online: April 9, 2018

(C) The Author(s) 2018

\section{ABSTRACT}

Introduction: The aim of this study is to assess the cost-effectiveness of golimumab for the treatment of non-radiographic axial spondyloarthritis (nr-axSpA) vs. conventional therapy and other tumor necrosis factor inhibitors from the Scottish payer perspective.

Methods: A model comprising a short-term decision tree and a long-term Markov model was developed to compare cost-effectiveness (incremental costs per quality-adjusted life-year [QALY]) for patients in Scotland with nr-axSpA treated by conventional therapy, adalimumab, certolizumab pegol, etanercept, or golimumab for a lifetime period. A network meta-analysis (NMA) was conducted to identify clinical and safety data for treatments and synthesize the available evidence into relative treatment effects between comparators. The probability of patients achieving an Assessment of SpondyloArthritis International Society 20/40\% response criteria (ASAS20/ASAS40) or a 50\% improvement in Bath Ankylosing Spondylitis

Enhanced content To view enhanced content for this article go to https://doi.org/10.6084/m9.figshare.59930 29.

R. H. Borse $(\square) \cdot S$. Kachroo · R. P. Insinga

Merck \& Co., Inc., Kenilworth, NJ, USA

e-mail: rebekah.borse@merck.com

C. Brown · E. McCann

Merck Sharp \& Dohme, Hoddesdon, UK
Disease Activity Index score (BASDAI50) at week 12 was obtained from the NMA for each of the comparators. Baseline health state utilities were based on the EQ-5D questionnaire collected in the golimumab GO-AHEAD study. The cost of treatment was calculated based on drug acquisition, drug administration, and initiation/monitoring costs.

Results: Golimumab resulted in an increase of 2.06 QALYs and additional cost of $£ 39,770$ compared with conventional therapy. Incremental cost per QALY gained was $£ 19,280$ for golimumab, which was lower than adalimumab $(£ 19,737)$, etanercept $(£ 20,089)$, and higher than certolizumab pegol $(£ 18,710)$. Golimumab remained cost-effective throughout a range of sensitivity analyses where key assumptions were tested.

Conclusions: From a Scottish perspective, golimumab was a cost-effective treatment for nraxSpA compared with conventional therapy at a willingness-to-pay threshold of $£ 30,000$ per QALY.

Funding: Merck \& Co., Inc.

Keywords: Ankylosing spondylitis; Costeffectiveness; Decision tree; Golimumab; Markov model; Non-radiographic axial spondyloarthritis; Scotland; Tumor necrosis factor inhibitors 


\section{INTRODUCTION}

Axial spondyloarthritis (axSpA) is a group of chronic, inflammatory diseases, primarily characterized by inflammation of the spine and sacroiliac joints [1]. The most commonly occurring form of axSpA is ankylosing spondylitis (AS), with radiographic structural changes in sacroiliac joints being the most important criterion for a clinical diagnosis [2]. In 2009, the Assessment of Spondyloarthritis International Society (ASAS) developed new classification criteria in order to better characterize the group of patients with typical features of axSpA, such as the presence of inflammatory back pain and positive human leukocyte antigen B27 (HLA-B27), but the absence of any definitive radiographic evidence of sacroiliitis [3]. This subpopulation is classified as having non-radiographic axial spondyloarthritis (nraxSpA) [3]. Both European data and Scotlandspecific data on the prevalence of nr-axSpA are very limited because of the different diagnostic criteria adopted in identifying patients with nraxSpA based on symptom duration, and varying availability of diagnostic tools. In Europe, the proportion of nr-axSpA among axSpA patients is estimated to be $23-80 \%$ [4]. The use of the ASAS classification criteria in identifying nr-axSpA patients in clinical practice was reported to be approximately 52\% (ranging from $24 \%$ in Germany to $75 \%$ in Spain) by a recent European cross-sectional study [5].

Some nr-axSpA patients will progress to AS later in their disease course while approximately $30 \%$ will never develop radiographic sacroiliitis despite persistent inflammatory back pain $[4,6]$. Studies report that the factors associated with disease progression include male sex, high level of inflammation (as demonstrated by C-reactive protein level), and longer symptom duration [7-9]. Patients treated with a tumor necrosis factor inhibitor (TNFi) also have slower rate of disease progression, compared with patients who have never been treated with a TNFi [5].

Regardless of whether progression to AS occurs, nr-axSpA can have substantial negative impacts on patients' daily activities and quality of life due to disease-related symptoms and treatment-related adverse events, as well as the functional effects of living with the disease. A number of studies have shown that physical function is considerably impaired among patients with nr-axSpA, as assessed with the Bath Ankylosing Spondylitis Disease Activity Index (BASDAI) and the Bath Ankylosing Spondylitis Functional Index (BASFI), with the Bath Ankylosing Spondylitis Metrology Index (BASMI) being used to assess spinal mobility $[7,8,10,11]$. Studies have shown that, compared with axSpA, nr-axSpA has a greater impact on productivity, both at home and in the workplace $[12,13]$. As would be expected, these effects translate to an increased economic burden, with healthcare-resource utilization and lost productivity resulting in approximate mean 3-year costs of between $€ 5000$ and $€ 38,000$ in a mixed cohort of SpA patients, the majority of whom had nr-axSpA [14].

Non-steroidal anti-inflammatory drugs (NSAIDs) are recommended as first-line treatment for nr-axSpA by ASAS and the European League Against Rheumatism (EULAR) [15]. Some patients respond well to initial treatment with NSAIDs, but a considerable proportion of patients have an inadequate response and will need subsequent treatment such as TNFi therapy to control persistently high disease activity. Currently, there are four TNFis (adalimumab, certolizumab pegol, etanercept, and golimumab) with marketing authorization for the treatment of nr-axSpA in Europe, when patients have high disease severity despite adequate NSAID treatment (a minimum of two NSAIDs for a minimum of 4 weeks) [15]. In addition, golimumab, adalimumab, etanercept, and certolizumab pegol are recommended by the Scottish Medicines Consortium (SMC) for the treatment of patients with nr-axSpA $[16,17]$.

Golimumab is a once-a-month, subcutaneously injected treatment for nr-axSpA that has been approved for previously treated nraxSpA in Europe. GO-AHEAD, a 16-week, phase 3 , placebo-controlled randomized trial, demonstrated the efficacy and tolerability of golimumab in patients with nr-axSpA who were not responding to NSAIDs [18]. Significantly more patients in the golimumab group achieved ASAS 20\% response criteria (ASAS20), 
compared with the placebo group at week 16 (71.1 vs. $40.0 \%, P<0.0001$ ), when looking at the full analysis set. In part 2 of GO-AHEAD, where patients in the golimumab group continued to receive golimumab, and patients in the placebo group crossed over to receive golimumab, the proportion of ASAS20 responders in the golimumab/golimumab group continued to increase from week 16 to week 32, and in the placebo/golimumab group, there was a notable increase in patients achieving ASAS20 after switching to golimumab [18].

The objective of this analysis was to assess the cost-effectiveness of golimumab for treatment of nr-axSpA vs. conventional therapy (including NSAIDs, cyclooxygenase-2 inhibitors, steroids, gastro-protectants, bisphosphonates, and physiotherapy) and other TNFis, namely adalimumab, certolizumab pegol, and etanercept, from the perspective of payer in Scotland.

\section{METHODS}

\section{Study Design}

A static decision model comprising an initial, short-term decision tree and a Markov model was developed for Scotland to compare cost-effectiveness outcomes for patients with nr-axSpA treated with conventional therapy, or TNFis. The decision tree modeled the potential for continuation or discontinuation of patients from TNFis based on response to treatment at 12 weeks. The first cycle of the Markov model then started, with the first transitions between Markov health states being applied at 24 weeks.

The model incorporated the BASDAI, BASDAI50, ASAS20, and ASAS40 scores. BASDAI is a validated instrument completed by patients, consisting of six $10-\mathrm{cm}$ horizontal visual analogue scales (VAS) to measure severity of fatigue, spinal and peripheral joint pain, localized tenderness, and morning stiffness, with the final BASDAI score ranging from 0 to 10 [19]. BASDAI50 has been recommended by the ASAS as the response criterion used to determine treatment success. The ASAS score is a composite measure, comprising a $10-\mathrm{cm}$ horizontal VAS for pain, inflammation, well-being, and function. Improvement in three modalities by $20 \%$ or more, without deterioration in the fourth modality, constitutes an ASAS20 response, and $40 \%$ or more an ASAS40 response [20].

This study is a modeling study using data derived from previously conducted studies, and does not contain any new studies with human or animal subjects performed by any of the authors.

\section{Model Structure}

\section{Decision Tree}

The decision tree provided estimates of expected costs and outcomes over the short term (Fig. 1a). Patients were initially managed with either a TNFi or conventional therapy. The model assumed that no patient discontinued conventional therapy and that no switching between different types of conventional therapy occurred. For patients who started treatment with a TNFi, a probability of remaining on TNFi treatment was assigned based on response to treatment (achieving ASAS20, ASAS40, or BASDAI50) informed by data from the GO-AHEAD study. Very few patients $(<5 \%)$ discontinued golimumab treatment prior to week 12 of GOAHEAD. It was therefore assumed that discontinuation of TNFis did not occur prior to week 12. Discontinuation at week 12 occurred if the patient did not have a treatment response according to the efficacy results. As there are no published data on long-term persistence with the modeled TNFis in a large Scottish or UK population of patients with nr-axSpA, following week 12 an annual rate of discontinuation of $5 \%$ was assumed in the model base case. Responders were assumed to stay on the same TNFi treatment and not switch to a second TNFi. Non-responders to TNFis who switched to conventional therapy remained in that state for the remainder of the model.

\section{Markov Model}

The Markov model provided estimates of expected costs and outcomes over the long term (Fig. 1b). Patients entered the Markov model following the initial decision tree. The Markov 


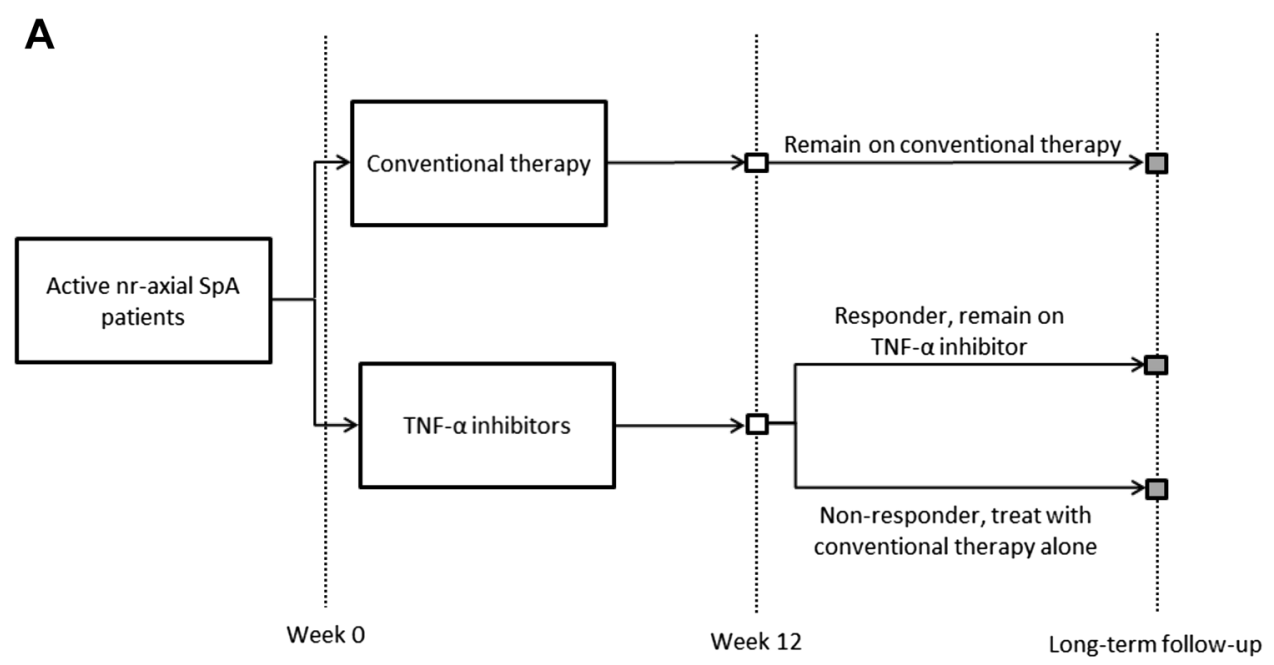

B

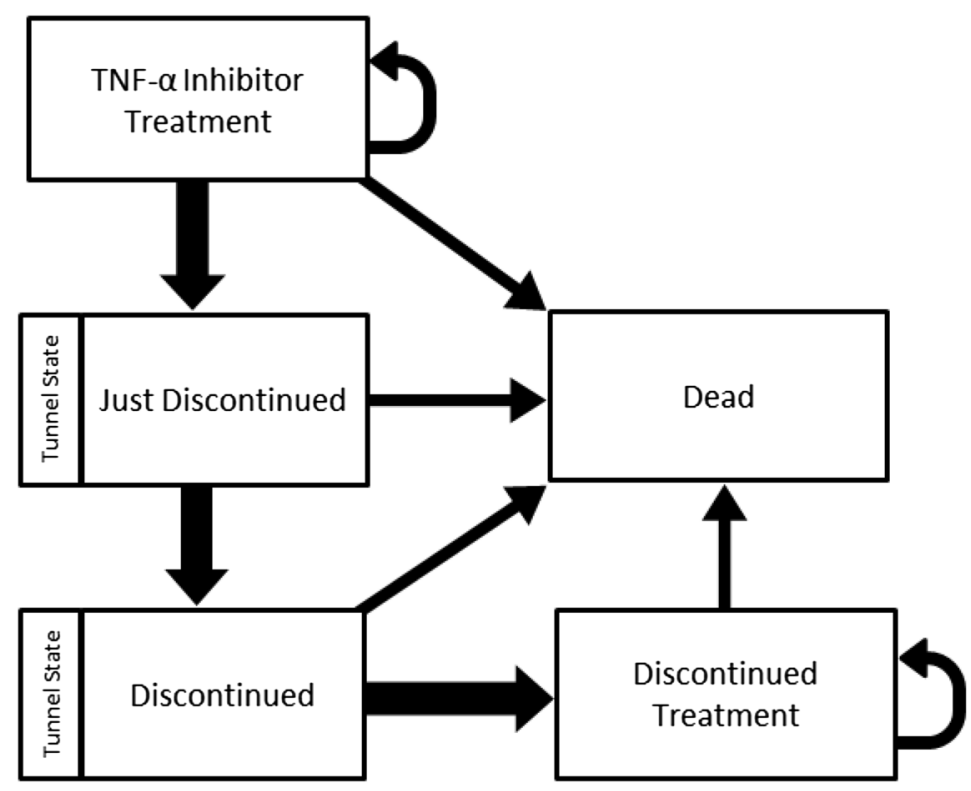

Fig. 1 Short-term decision tree (a) and long-term Markov model (b). a Short-term decision tree ${ }^{a} .{ }^{a}$ The decision tree model represents the clinical decision that can be taken at 12 weeks (informed by treatment response) to either continue or discontinue treatment with TNFis. Responders were assumed to stay on the same TNFi treatment. Non-responders who switched onto conventional therapy remained on conventional therapy for the remainder of the model time horizon. Patients who started on conventional therapy remained on conventional therapy throughout the model, irrespective of the probability of response at Week 12. b Long-term Markov model ${ }^{a}$. ${ }^{a}$ Patients entered the Markov model, following the initial decision tree, after week 12. Patients treated with a TNFi either stayed on (the same) treatment or discontinued treatment. For patients who discontinued treatment, the transition from the 'TNFi Treatment' state to the 'Discontinued Treatment' state was assumed to take 24 weeks (two cycles). Discontinuing patients first moved to the 'Just Discontinued' tunnel state and remained in that state for one cycle and then moved to the 'Discontinued' tunnel state and remained in that state for one cycle. Patients in the 'Discontinued Treatment' state were thereafter assumed to receive conventional therapy alone. Patients could die while in any of the health states. $n r-a x S p A$ Nonradiographic axial spondyloarthritis; $T N F i$ Tumor necrosis factor inhibitor 
model comprised defined, mutually exclusive health states through which patients transitioned at a rate, which was dependent on the rate of disease progression and the age-/sexspecific standardized mortality rate (SMR) (patients could die while in any of the health states) for people with nr-axSpA, which was assumed to be the same as for patients with AS [21]. A 12-week model cycle was used. Cost and utility data were summed by treatment arm as the model progressed cycle by cycle, allowing for the calculation of incremental costs and effectiveness per treatment.

Patients treated with a TNFi either stayed on treatment or discontinued. The proportions of patients discontinuing treatment were assumed to be the same for all TNFis. An annual discontinuation rate of $5 \%$ was applied for the remainder of the model time horizon, informed by the golimumab arm in the GO-AHEAD study.

If discontinuing treatment, patients first moved to the 'Just Discontinued' tunnel state and remained in that state for one cycle and then moved to the 'Discontinued' tunnel state and remained in that state for one cycle. Tunnel states are modeled to assist with modeling a linear resolution of treatment effect following treatment discontinuation over a 24 -week period. Patients then moved to the 'Discontinued Treatment' state. It was assumed once entering the 'Discontinued treatment' state patients' disease progression rebounded to the level as if they had been treated with conventional care alone. Patients in the 'Discontinued Treatment' state were thereafter assumed to receive conventional therapy alone. Patients could die while in any of the health states.

\section{Efficacy Measurements}

There are no head-to-head trials investigating the efficacy and safety of golimumab compared to other TNFis, and data informing comparative efficacy between treatment options of nr-axSpA are very limited. Therefore, a systematic literature review (SLR) and a network meta-analysis (NMA) were conducted to identify all relevant treatments and synthesize the available evidence into relative treatment effects between comparators. Conventional therapy, adalimumab, certolizumab pegol, and etanercept were included as comparators in the model based on their relevance to current clinical practice in managing nr-axSpA.

GO-AHEAD compared golimumab to conventional therapy, providing direct evidence on the comparative efficacy of these two treatments. As well as GO-AHEAD, the SLR identified published data from the comparator trials, including two phase 3 trials investigating adalimumab $[22,23]$, one phase 3 trial on certolizumab pegol [24], and two phase 3 trials on etanercept $[25,26]$. In each trial, the TNFi was compared to conventional therapy. The relative treatment effects were established by the NMA based on the identified data in a fixed effects model (as due to multiple treatment comparators only having data from a single trial available, there were insufficient trials to estimate the heterogeneity parameter for a random effects model).

\section{Model Inputs}

\section{Transition Probabilities}

The probability of patients achieving an ASAS20, ASAS40, or BASDAI50 response at week 12 was obtained from the NMA for each of the TNFis and for conventional therapy. BASDAI50 was used as the efficacy measure in the model base case because this represents the measure for treatment response most commonly used in Scottish clinical practice as informed through seeking expert input.

Disease progression was demonstrated by change in BASDAI and BASFI scores. Baseline BASDAI and BASFI scores were based on baseline scores from the GO-AHEAD study, for both conventional therapy and TNFis, and were assumed to be identical for all TNFis. The magnitude of response to conventional therapy was informed by the change in BASDAI and BASFI scores at week 12 in GO-AHEAD, and the magnitude of response to TNFis was derived from the NMA.

The NMA demonstrated that there were no statistically significant differences in any adverse events, any serious adverse events, or infections (clinically significant opportunistic 
infections) between TNFis or with respect to conventional therapy.

\section{Utilities}

Baseline health state utility values were based on the EQ-5D health questionnaire collected in the GO-AHEAD study alongside the BASDAI and BASFI scores. A regression equation [27] using those baseline EQ-5D scores observed in the GO-AHEAD study was constructed to estimate the average change in EQ-5D score per 1 unit change in BASDAI and BASFI scores. In order to estimate the EQ-5D score at each cycle, the following equation that accounted for age and sex was used to elicit the change in EQ-5D. The average baseline utility score of the cohort was 0.43 .

$$
\begin{aligned}
\mathrm{EQ}-5 \mathrm{D}= & 0.43+(0.10034-0.05735 \\
& \times \mathrm{BASDAI}-0.03120 \times \mathrm{BASFI} \\
& +0.00126 \times \text { Sex }-0.00440 \times \text { Age })
\end{aligned}
$$

\section{Costs}

The cost of treatment was calculated based on drug acquisition, drug administration, and initiation/monitoring costs. All treatment strategies included conventional therapy and thus the costs associated with conventional therapy were not included in the model.

The unit costs of TNFis were sourced from the British National Formulary [28]. Doses were in accordance with product licences $[16,17,29,30]$. TNFis were assumed to be selfadministered following instruction from a nurse. The cost of the instruction was $£ 50.00$, based on $1 \mathrm{~h}$ of patient-related nurse time [31]. This cost was only applied in the decision-tree component of the model (i.e., the first 12 weeks). Initiation and monitoring costs for TNFis were sourced from the National Institute for Health and Care Excellence (NICE) Multiple Technology Appraisal (MTA) for nr-axSpA and were inflated to $2013 / 14$ prices using the Hospital \& Community Health Services Pay \& Prices Index $[32,33]$. Annual disease management costs for nr-axSpA, beyond the treatment costs associated with TNFis, were applied based on a costing equation (NHS cost $=1284.186$ * $\operatorname{EXP}[0.213 \times$ BASFI $]$ ) derived from the
Outcomes in Ankylosing Spondylitis International Study (OASIS) [34]. This approach was validated by clinical experts in Scotland.

For adverse event costs, we included a weighted cost of infections and the weights were based on previous Health Technology Assessment submissions [35]. The cost of an infection was counted as a one-time cost and applied for one cycle in the model. The probabilities of infections for each TNFi were derived from the NMA. For simplicity, other adverse events were not modeled, as they would not be expected to have a substantive impact on model results and, even in the case of infection, there was little change in the incremental cost-effectiveness ratio (ICER) in one-way deterministic sensitivity analysis, as described in the Results section.

\section{Model Analyses}

The base-case analyses evaluated a lifetime time horizon and applied an annual discount rate of $3.5 \%$ to both costs and health benefits based on SMC's recommendations. Clinical outcomes were expressed as gains in quality-adjusted lifeyears (QALYs). Cost-effectiveness was measured in terms of incremental costs per QALY gained, comparing the incremental clinical benefit from golimumab versus other TNFis or conventional therapy.

A one-way deterministic sensitivity analysis (DSA) was used to identify the key drivers of uncertainty in the estimation of the incremental cost-effectiveness of golimumab. The key parameters varied in the DSA included time horizon, age at baseline, proportion of males, 12 -week treatment response measure, annual discontinuation rate with TNFis, annual disease progression (conventional therapy), annual disease progression post-week 260 (to account for the uncertainty of the long-term disease progression), data source for infections, longterm disease management costs, and utility decrement per one unit change in BASDAI/ BASFI. For continuous variables, where available, the standard deviation (SD) or standard error (SE) of each parameter was used to define the upper and lower values for the sensitivity 
analysis. Where the SD or SE was not available, the upper and lower limits of the range were defined either as 100 and $0 \%$ or $\pm 30 \%$ of the parameter. All other variables in the model were varied by $\pm 30 \%$ of the parameter.

A probabilistic sensitivity analysis (PSA) was also conducted for 10,000 replications to account for multivariate and stochastic uncertainty in the model from which the probabilistic ICER was calculated. The PSA was based on the base case. Distributions for parameters were based on recommendations by Briggs et al. [36].

The model was based on the approach used in the previous submission for the NICE MTA (for AS), which was informed by McLeod et al. [27]. Following review of the submission, amendments to that model were made to adapt it to $\mathrm{nr}$-axSpA where required and to address uncertainties raised by the NICE MTA Assessment Group. The model has since been revalidated by an independent health economist.

The results are discussed in relation to the SMC and a Scottish population, with discussion based around a willingness-to-pay (WTP) threshold of $£ 30,000$, as well as $£ 20,000$ WTP for comparative purposes.

\section{RESULTS}

The baseline characteristics of patients used in the base case of the model were informed by the GO-AHEAD trial and are summarized in Table 1. The mean age of the trial population was 31.2 years ( $\mathrm{SE}=0.51$ years) and $57.1 \%$ were male. As expected, disease activity was high for this group of patients (mean BASDAI $=6.5$ ) [18]. Golimumab was associated with better clinical outcomes than conventional therapy, as demonstrated by significantly higher proportions of patients in the golimumab group achieving BASDAI50, ASAS20, and ASAS40 responses (median $\mathrm{OR}=3.2,3.6$, and 6.0, respectively). Specifically, 45.8, 64.6, and 51.7\% of the golimumab arm achieved a BASDAI50, ASAS20, and ASAS40 response, respectively, compared with $20.7,33.8$, and $15.2 \%$ of patients receiving conventional therapy, respectively. When comparing the efficacy outcomes of golimumab with that of other TNFis, results from the
NMA show that there is no significant difference (the confidence intervals crossed 1 for head-tohead comparisons with adalimumab, etanercept, and certolizumab pegol).

The total cost of administering golimumab is estimated to be $£ 2667.72$ for the first cycle of 12 weeks, and $£ 2195.22$ for subsequent cycles, and includes drug acquisition, drug administration, and monitoring costs. Golimumab resulted in an increase of 2.06 QALYs when compared with use of conventional therapy. Incremental costs per QALY gained were $£ 19,280$ for golimumab, and $£ 19,737, £ 18,710$, and $£ 20,089$ for adalimumab, certolizumab pegol, and etanercept, respectively. Base case results are shown in Table 2.

Results from the one-way DSA comparing golimumab vs. conventional therapy demonstrated that no variable, when altered, produced an ICER greater than $£ 30,000$ (except when the time horizon was limited to 1 year) (Table 3 ). The effect of an increase in the cost of golimumab after week 12 (from $£ 2195.22$ to $£ 2853.79$ ) increased the incremental cost vs. conventional therapy and produced a higher ICER (from $£ 19,280$ to $£ 26,290$ ); this estimated ICER was still lower than a $£ 30,000$ WTP threshold. Uncertainty surrounding all other variables had a minimal impact on the estimated ICERs. The one-way DSA performed for all other variables showed that the ICER of golimumab versus conventional therapy was most sensitive to the drivers shown in Fig. 2.

The 10,000 samples run in the PSA produced an average ICER of $£ 18,291$ for golimumab versus conventional therapy. The cost-effectiveness acceptability curve estimating the probability of golimumab being cost-effective vs. conventional therapy is displayed in Fig. 3. At a WTP threshold of $£ 20,000$, there was a $57.5 \%$ probability that golimumab was cost-effective. At a WTP threshold of $£ 30,000$, there was an $86.5 \%$ probability that golimumab was cost-effective.

\section{DISCUSSION}

This economic model was designed to evaluate the cost-effectiveness of golimumab in treating 
Table 1 Base case inputs and assumptions

\begin{tabular}{|c|c|c|c|}
\hline Variable & Value & Range & Distribution \\
\hline \multicolumn{4}{|l|}{ Key variables } \\
\hline Time horizon & Lifetime & - & - \\
\hline Cycle length (weeks) & 12 & - & - \\
\hline Discount rate (\%) & 3.5 & - & - \\
\hline Starting age in the model (years) & 31.2 & SD 0.51 & Normal, truncated \\
\hline Sex, proportion of males (\%) & 57.1 & - & - \\
\hline \multicolumn{4}{|l|}{ Standardized mortality rate (SMR) } \\
\hline Male & 1.63 & SE 0.17 & Lognormal \\
\hline Female & 1.38 & SE 0.46 & Lognormal \\
\hline \multicolumn{4}{|l|}{ Baseline scores } \\
\hline BASDAI score & 6.49 & SD 0.12 & Normal, truncated \\
\hline BASFI score & 5.01 & SD 0.19 & Normal, truncated \\
\hline Baseline utility & 0.43 & SD 0.03 & Normal, truncated \\
\hline \multicolumn{4}{|l|}{ Probability of week-12 response ${ }^{\mathrm{a}}$} \\
\hline Conventional therapy & 0.2069 & SD 0.02091 & Beta \\
\hline Golimumab & 0.4575 & SD 0.08065 & Lognormal \\
\hline Adalimumab & 0.4642 & SD 0.08375 & Lognormal \\
\hline Certolizumab pegol & 0.5578 & SD 0.117 & Lognormal \\
\hline Etanercept & 0.3974 & SD 0.07659 & Lognormal \\
\hline \multicolumn{4}{|l|}{ Week-12 scores } \\
\hline \multicolumn{4}{|l|}{ Conventional therapy } \\
\hline BASDAI score & 5.20 & - & Normal, truncated \\
\hline BASFI score & 4.34 & - & Normal, truncated \\
\hline \multicolumn{4}{|l|}{ Golimumab } \\
\hline BASDAI score & 3.35 & - & Normal, truncated \\
\hline BASFI score & 2.71 & - & Normal, truncated \\
\hline \multicolumn{4}{|l|}{ Adalimumab } \\
\hline BASDAI score & 4.17 & - & Normal, truncated \\
\hline BASFI score & 3.60 & - & Normal, truncated \\
\hline \multicolumn{4}{|l|}{ Certolizumab pegol } \\
\hline BASDAI score & 3.35 & - & Normal, truncated \\
\hline BASFI score & 2.45 & - & Normal, truncated \\
\hline
\end{tabular}


Table 1 continued

\begin{tabular}{|c|c|c|c|}
\hline Variable & Value & Range & Distribution \\
\hline \multicolumn{4}{|l|}{ Etanercept } \\
\hline BASDAI score & 4.50 & - & Normal, truncated \\
\hline BASFI score & 3.74 & - & Normal, truncated \\
\hline \multicolumn{4}{|l|}{ Week-24 scores } \\
\hline \multicolumn{4}{|c|}{ Conventional therapy } \\
\hline BASDAI score & 5.22 & - & Normal, truncated \\
\hline BASFI score & 4.36 & - & Normal, truncated \\
\hline \multicolumn{4}{|l|}{ TNFis } \\
\hline BASDAI score & 1.00 & - & Normal, truncated \\
\hline BASFI score & 0.92 & - & Normal, truncated \\
\hline \multicolumn{4}{|l|}{ Week-36 scores } \\
\hline \multicolumn{4}{|c|}{ Conventional therapy } \\
\hline BASDAI score & 5.23 & - & Normal, truncated \\
\hline BASFI score & 4.38 & - & Normal, truncated \\
\hline \multicolumn{4}{|l|}{ TNFis } \\
\hline BASDAI score & 0.85 & - & Normal, truncated \\
\hline BASFI score & 0.88 & - & Normal, truncated \\
\hline \multicolumn{4}{|l|}{ Week-48 scores } \\
\hline \multicolumn{4}{|c|}{ Conventional therapy } \\
\hline BASDAI score & 5.25 & - & Normal, truncated \\
\hline BASFI score & 4.39 & - & Normal, truncated \\
\hline \multicolumn{4}{|l|}{ TNFis } \\
\hline BASDAI score & 0.93 & - & Normal, truncated \\
\hline BASFI score & 0.87 & - & Normal, truncated \\
\hline \multicolumn{4}{|l|}{ Week-60 scores } \\
\hline \multicolumn{4}{|c|}{ Conventional therapy } \\
\hline BASDAI score & 5.26 & - & Normal, truncated \\
\hline BASFI score & 4.41 & - & Normal, truncated \\
\hline \multicolumn{4}{|l|}{ TNFis } \\
\hline BASDAI score & 0.92 & - & Normal, truncated \\
\hline BASFI score & 0.85 & - & Normal, truncated \\
\hline
\end{tabular}


Table 1 continued

\begin{tabular}{|c|c|c|c|c|}
\hline \multicolumn{2}{|l|}{ Variable } & Value & Range & Distribution \\
\hline \multicolumn{5}{|l|}{ Probability of infections } \\
\hline \multicolumn{2}{|l|}{ Conventional therapy } & 0.2096 & SD 0.02222 & Beta \\
\hline \multicolumn{2}{|l|}{ Golimumab } & 0.2315 & SD 0.06379 & Lognormal \\
\hline \multicolumn{2}{|l|}{ Adalimumab } & 0.2674 & SD 0.06028 & Lognormal \\
\hline \multicolumn{2}{|l|}{ Certolizumab pegol } & 0.24945 & - & - \\
\hline \multicolumn{2}{|l|}{ Etanercept } & 0.242 & SD 0.08712 & Lognormal \\
\hline \multicolumn{5}{|l|}{ Probability of SAEs } \\
\hline \multicolumn{2}{|l|}{ Conventional therapy } & 0.01641 & SD 0.006948 & Beta \\
\hline \multicolumn{2}{|l|}{ Golimumab } & 0.01541 & SD 0.02999 & Lognormal \\
\hline \multicolumn{2}{|l|}{ Adalimumab } & 0.07749 & SD 0.1025 & Lognormal \\
\hline \multicolumn{2}{|l|}{ Certolizumab pegol } & 0.046 & - & - \\
\hline \multicolumn{2}{|l|}{ Etanercept } & 0.02995 & SD 0.04751 & Lognormal \\
\hline \multicolumn{5}{|c|}{ 12-week cycle costs (drug acquisition, drug administration, initiation/monitoring) } \\
\hline \multirow[t]{2}{*}{ Golimumab } & First 12 weeks & 2667.72 & SE 800.315 & Gamma \\
\hline & Subsequent cycles & 2195.22 & SE 658.566 & Gamma \\
\hline \multirow[t]{2}{*}{ Adalimumab } & First 12 weeks & 2667.72 & SE 800.315 & Gamma \\
\hline & Subsequent cycles & 2195.22 & SE 658.566 & Gamma \\
\hline \multirow[t]{2}{*}{ Certolizumab pegol } & First 12 weeks & 554.88 & SE 166.463 & Gamma \\
\hline & Subsequent cycles & 2227.38 & SE 668.214 & Gamma \\
\hline \multirow[t]{2}{*}{ Etanercept } & First 12 weeks & 2699.88 & SE 809.963 & Gamma \\
\hline & Subsequent cycles & 2227.38 & SE 668.214 & Gamma \\
\hline \multicolumn{5}{|l|}{ Other costs } \\
\hline \multirow[t]{2}{*}{ Long-term costs } & Intercept & 1284.186 & SE 385.2558 & Normal \\
\hline & Coefficient BASFI score & 0.213 & SE 0.0639 & Normal \\
\hline \multicolumn{2}{|l|}{ Infection } & 1483.226 & SE 444.97 & Gamma \\
\hline \multicolumn{5}{|l|}{ Other variables } \\
\hline \multicolumn{2}{|c|}{ Annual disease progression (conventional therapy) } & 0.07 & SD 0.021 & Normal, truncated \\
\hline \multicolumn{2}{|c|}{ Annual disease progression post-Week 260 (TNFis) } & $0.50^{\mathrm{b}}$ & - & - \\
\hline \multicolumn{2}{|c|}{ Annual discontinuation rate (TNFis) } & 5.0 & SE 0.015 & Beta \\
\hline \multicolumn{2}{|c|}{ Intercept for utility score } & 0.10034 & SE 0.11562 & Normal \\
\hline
\end{tabular}


Table 1 continued

\begin{tabular}{lllll}
\hline Variable & & Value & Range & Distribution \\
\hline Coefficient for utility score & Sex & 0.00126 & SE 0.04384 & Normal \\
& Age & -0.0044 & SE 0.0031 & Normal \\
& Per 1 unit change in BASDAI & -0.05735 & SE 0.01343 & Normal \\
& Per 1 unit change in BASFI & -0.0312 & SE 0.01302 & Normal \\
Disutility for SAEs & & 0.01 & SE 0.003 & Normal \\
\hline
\end{tabular}

$B A S D A I$ bath ankylosing spondylitis disease activity index, $B A S F I$ bath ankylosing spondylitis functional index, $S A E$ serious adverse event, $S D$ standard deviation, $S E$ standard error, $T N F i$ tumor necrosis factor inhibitor

${ }^{a}$ According to a BASDAI50 response (this efficacy measure was used in the model base case to reflect Scottish clinical practice)

b Assumed to occur at $50 \%$ of the rate of progression on conventional therapy

Table 2 Base case results

\begin{tabular}{llllll}
\hline Treatment & $\begin{array}{l}\text { Total costs } \\
(\boldsymbol{E})\end{array}$ & $\begin{array}{l}\text { Total } \\
\text { QALYs }\end{array}$ & $\begin{array}{l}\text { Incremental costs } \\
(\boldsymbol{E})\end{array}$ & $\begin{array}{l}\text { Incremental } \\
\text { QALYs }\end{array}$ & $\begin{array}{l}\text { ICER } \\
(\boldsymbol{E})\end{array}$ \\
\hline $\begin{array}{l}\text { Conventional therapy } \\
\quad \text { (reference) }\end{array}$ & 107,138 & 6.93 & - & - & - \\
Golimumab & 146,908 & 9.00 & 39,770 & 2.06 & 19,280 \\
Adalimumab & 148,247 & 9.02 & 41,110 & 2.08 & 19,737 \\
Certolizumab pegol & 154,233 & 9.45 & 47,095 & 2.52 & 18,710 \\
Etanercept & 142,933 & 8.72 & 35,795 & 1.78 & 20,089 \\
\hline
\end{tabular}

ICER Incremental cost-effectiveness ratio, QALY Quality-adjusted life-year

patients with active nr-axSpA who had inadequate response to NSAID treatment, from the SMC perspective. The base case results indicated approximately 2.06 QALYs gained for golimumab patients and an ICER of $£ 19,280$ relative to patients treated with conventional therapy.

The robustness of the base case analysis was supported by extensive sensitivity analyses, where the cost-effectiveness of golimumab was relatively stable across different scenarios. Golimumab remained a cost-effective treatment regardless of whether BASDAI50, ASAS20, or ASAS40 were used to define treatment. The oneway DSA of golimumab vs. conventional therapy demonstrated that no variable, when altered, produced an ICER greater than $£ 30,000$, which is the WTP threshold typically applied by the SMC.
This analysis has several strengths. The short-term decision tree and Markov model were designed to capture the unique aspects of $\mathrm{nr}-\mathrm{axSpA}$ and the treatment pathway in question. The short-term decision tree represents the clinical decision that can be taken at 12 weeks to either continue or discontinue treatment with TNFis. This is in line with the Summary of Product Characteristics of the TNFis $[16,17,28,29]$, which states that clinical response is usually achieved within 12 weeks. The Markov model then depicts the transitioning of patients from one health state to another based on disease progression and age-/sexspecific mortality rates.

Secondly, a key data source for our model was the GO-AHEAD trial, a phase 3, randomized controlled trial comparing the efficacy and safety of golimumab with conventional 
Table 3 Effect of key variables on the ICER from one-way DSA

\begin{tabular}{|c|c|c|c|c|}
\hline Variable & $\begin{array}{l}\text { Model base } \\
\text { case value }\end{array}$ & $\begin{array}{l}\text { Sensitivity } \\
\text { analysis value }\end{array}$ & Rationale & $\begin{array}{l}\text { ICER for golimumab vs. } \\
\text { conventional therapy }(\boldsymbol{E})\end{array}$ \\
\hline Model base case & & & & 19,280 \\
\hline \multirow[t]{2}{*}{ Time horizon } & \multirow[t]{2}{*}{ Lifetime } & 1 year & \multirow{2}{*}{$\begin{array}{l}\text { Bansback et al. } 2007 \\
{[38]}\end{array}$} & 37,556 \\
\hline & & 10 years & & 21,907 \\
\hline Age at baseline & 31.2 years & 60.0 years & $\begin{array}{l}\text { Tested in NICE MTA } \\
\text { for nrax-SpA [39] }\end{array}$ & 20,616 \\
\hline \multirow[t]{2}{*}{ Sex, males } & \multirow[t]{2}{*}{$57.1 \%$} & $100 \%$ & \multirow[t]{2}{*}{ Maximum values } & 19,342 \\
\hline & & $0 \%$ & & 19,188 \\
\hline \multirow{2}{*}{$\begin{array}{l}\text { 12-week treatment response } \\
\text { measure }\end{array}$} & \multirow[t]{2}{*}{ BASDAI50 } & ASAS20 & Alternative efficacy & 19,539 \\
\hline & & ASAS40 & measures & 19,153 \\
\hline \multirow{2}{*}{$\begin{array}{l}\text { Annual discontinuation rate } \\
\text { with TNFis }\end{array}$} & \multirow[t]{2}{*}{$5.0 \%$} & $3.5 \%$ & $\pm 30 \%$ & 18,785 \\
\hline & & $6.5 \%$ & & 19,712 \\
\hline \multirow{2}{*}{$\begin{array}{l}\text { Annual disease progression } \\
\text { (conventional therapy) }^{\mathrm{a}}\end{array}$} & \multirow[t]{2}{*}{0.07} & 0.03 & Kobelt et al. 2004 [40] & 21,427 \\
\hline & & 0.09 & & 18,248 \\
\hline \multirow{2}{*}{$\begin{array}{l}\text { Annual disease progression post- } \\
\text { week } 260 \text { (TNFis) }\end{array}$} & \multirow[t]{2}{*}{$50 \%$} & $100 \%$ & Maximum values & 20,556 \\
\hline & & $0 \%$ & & 18,157 \\
\hline \multirow{2}{*}{$\begin{array}{l}\text { Standardized mortality rate } \\
\text { (SMR) }\end{array}$} & Men $: 1.63$ & $1.467-1.793$ & $\pm 10 \%$ & 19,253 \\
\hline & Women:1.38 & $1.242-1.518$ & & 19,306 \\
\hline \multirow[t]{2}{*}{ Data source for infections } & \multirow[t]{2}{*}{ NMA } & $\begin{array}{l}\text { None } \\
\text { assumed }\end{array}$ & Alternative sources & 19,075 \\
\hline & & $\begin{array}{l}\text { Cochrane } \\
\text { review }[41]\end{array}$ & & 19,151 \\
\hline \multirow{2}{*}{$\begin{array}{l}\text { Long-term disease management } \\
\text { costs }\end{array}$} & \multirow[t]{2}{*}{$100 \%$} & $130 \%$ & $\pm 30 \%$ & 17,608 \\
\hline & & $70 \%$ & & 20,952 \\
\hline \multirow{2}{*}{$\begin{array}{l}\text { Utility decrement per } 1 \text { unit } \\
\text { change in BASFI/BASDAI }\end{array}$} & \multirow[t]{2}{*}{$100 \%$} & $130 \%$ & $\pm 30 \%$ & 14,831 \\
\hline & & $70 \%$ & & 27,543 \\
\hline
\end{tabular}

ASAS20 assessment of Spondyloarthritis International Society 20\% Response Criteria, ASAS40 assessment of Spondyloarthritis International Society 40\% Response Criteria, BASDAI bath Ankylosing Spondylitis Disease Activity Index, BASDAI50 improvement in BASDAI score of 50\%, BASFI Bath Ankylosing Spondylitis Functional Index, DSA deterministic sensitivity analysis, ICER incremental cost-effectiveness ratio, $N M A$ network meta-analysis, $n r-a x S p A$ non-radiographic axial spondyloarthritis, TNFi tumor necrosis factor inhibitor

a Assumed to occur at $50 \%$ of the rate of progression on conventional therapy

therapy in a broad patient population with active nr-axSpA and an inadequate response to at least one NSAID treatment. In the absence of head-to-head trial data, for all the currently available treatment options, namely conventional therapy, golimumab, etanercept, adalimumab, certolizumab pegol $200 \mathrm{mg}$ and certolizumab pegol $400 \mathrm{mg}$, an SLR was 


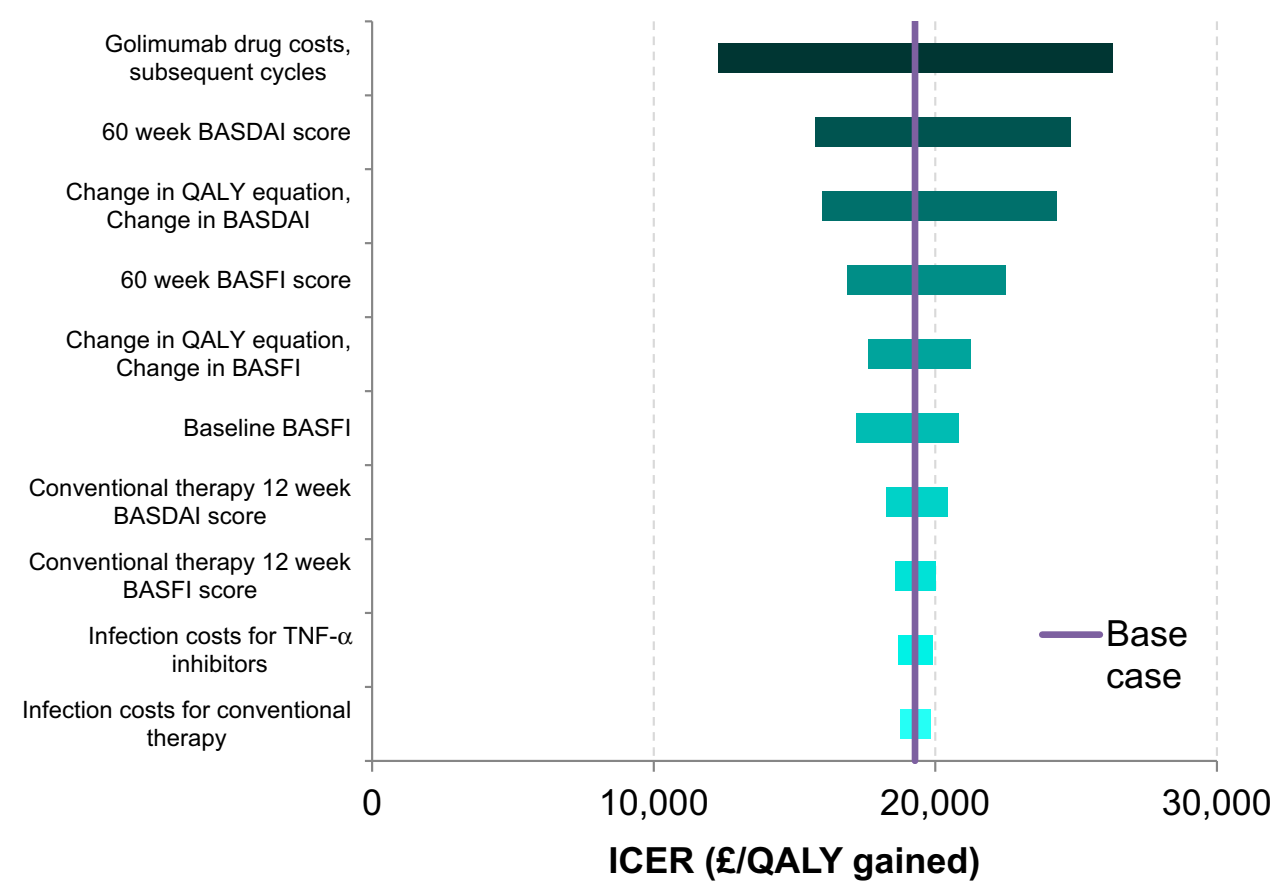

Fig. 2 Tornado diagram showing drivers affecting ICER of golimumab versus conventional therapy most. BASDAI Bath Ankylosing Spondylitis Disease Activity Index,
BASFI Bath Ankylosing Spondylitis Functional Index, $I C E R$ incremental cost-effectiveness ratio, QALY qualityadjusted life year

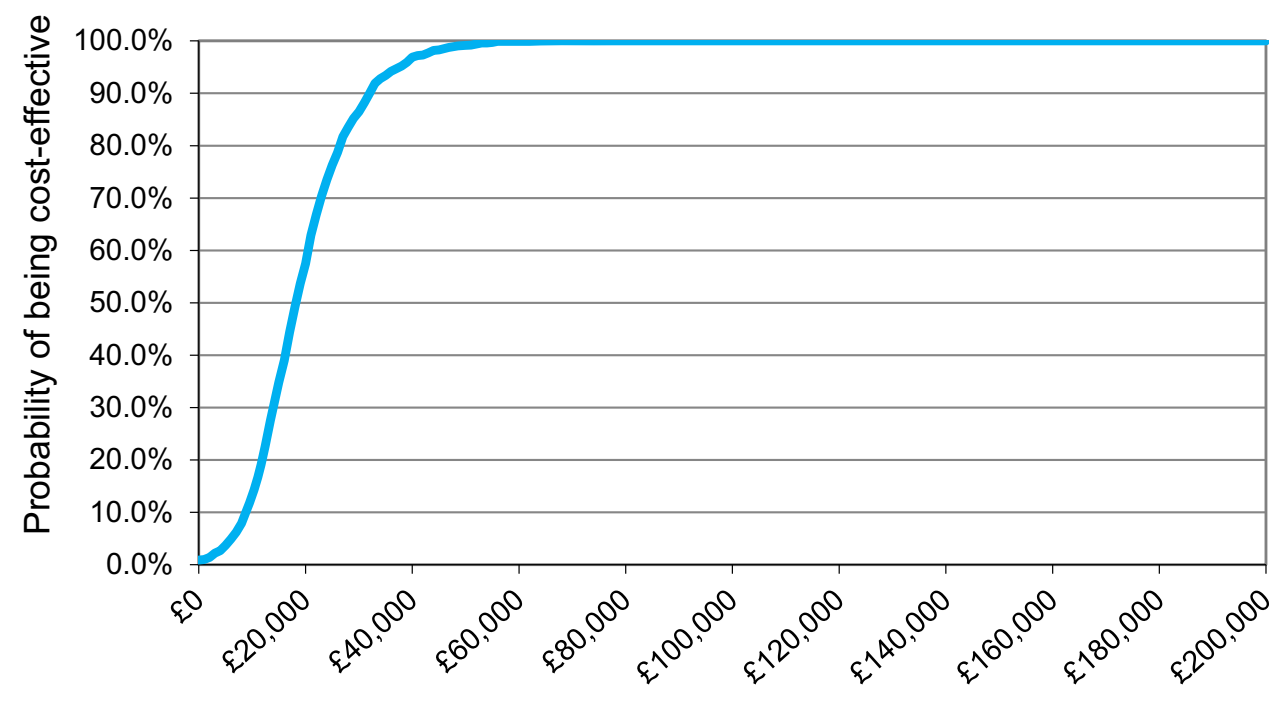

WTP Threshold

WTP, willingness-to-pay

Fig. 3 Cost-effectiveness acceptability curve of golimumab vs. conventional therapy. WTP willingness-to-pay

performed to identify and include eligible studies and the indirect comparison was informed by the NMA.
In addition, the model and the results derived from it are relevant and generalizable to Scotland, as the model was based upon a clinical 
analysis conducted in a population which reflects that of Scotland and all relevant comparator treatments from a Scottish perspective were included; moreover, the model incorporates variables that are relevant to Scottish clinical practice, such as using the BASDAI50 response to determine treatment response in the base case scenario.

Our analysis is nevertheless subject to limitations due to a lack of available data and the model assumptions. There are no head-to-head trial comparisons for the other TNFis with golimumab, and the relative treatment effects were obtained from the NMA, which may have introduced some uncertainty around the clinical benefits of the TNFis in the model. Given the overlapping confidence intervals for efficacy between the TNFis, comparisons of cost-effectiveness are unstable and may not reflect real differences in cost-effectiveness between TNFis. This is caused by the methodological limitations associated with combining data from different trials within an NMA and a relatively small network. However, since the main comparator in this analysis was conventional therapy, this is less likely to have an impact on the main outcomes. And we have examined the potential effect of such uncertainty on the ICER in the sensitivity analyses. In addition, our model assumed that patients receiving different TNFis had the same baseline BASDAI and BASFI scores at the time of TNFi initiation. It is possible that in clinical practice, disease severity of patients choosing to initiate one TNFi differ from that of patients initiating another TNFi. However, current clinical guidelines for management of nr-axSpA do not recommend one TNFi over another based on patient's BASDAI or BASFI score, therefore, we consider such an assumption reasonable in the context of this cost-effectiveness model. Our analysis also did not consider the wider benefits of patients receiving golimumab. As the only once-amonth self-injecting TNFi, golimumab may reduce productivity loss in patients with nraxSpA, as all other comparators require visits to a medical facility for IV infusions. In addition, in the UK, patients who receive golimumab treatment are also provided additional patient support programs, i.e., homecare services, and consequently reducing health system resources. These productivity and societal costs associated with nr-axSpA can cause a significant economic burden. Thus, inclusion of those wider costs may substantially further reduce ICERs compared with conventional therapy. Furthermore, mortality rates used in the Markov model were assumed to be the same as for AS and these data were taken from a single study [21]. This was the most current data available during model design. Newer data from a larger cohort suggested that SMR for AS were very close to our original assumptions, but the estimate of SMR for women was slightly higher than assumed in our study [37]. However, the results from DSA were not found to be remarkably sensitive to variation in mortality rates.

\section{CONCLUSIONS}

In conclusion, golimumab was demonstrated to be a cost-effective treatment for nr-axSpA compared with conventional therapy from a Scottish perspective, with an ICER of $£ 19,280$. Golimumab remained cost-effective throughout a range of sensitivity analyses where key assumptions were tested.

\section{ACKNOWLEDGEMENTS}

Funding. This work and the article processing charges was supported by Merck \& Co., Inc., Kenilworth, NJ USA. The sponsor was involved in the design of the study and writing of this manuscript but had no involvement in the data management, data analysis, or interpretation of the results. All authors had full access to all of the data in this study and take complete responsibility for the integrity of the data and accuracy of the data analysis.

Authorship. Rebekah H. Borse, Ralph P. Insinga, and Chloe Brown contributed to the study design. All authors contributed to data analysis, data interpretation, and planning and critical review of the manuscript content. All named authors meet the International 
Committee of Medical Journal Editors (ICMJE) criteria for authorship for this manuscript, take responsibility for the integrity of the work as a whole, and have given final approval to the version to be published.

\section{Medical Writing, Editorial, and Other} Assistance. The authors are grate-

ful to Christopher Hoyle and Ahmed Sowdani, previous employees of MSD UK, for programming support, and to Oonagh McGill (MSD UK), for guidance and leadership in planning the approach to this analysis. The authors received writing/editorial support in the preparation of this manuscript from Yunyu Huang, PhD, of Excerpta Medica, funded by Merck \& Co., Inc., Kenilworth, NJ, USA.

Disclosures. Rebekah H. Borse is an employee of Merck \& Co., Inc., Kenilworth, NJ, USA. Sumesh Kachroo is an employee of Merck \& Co., Inc., Kenilworth, NJ, USA. Ralph P. Insinga is an employee of Merck \& Co., Inc., Kenilworth, NJ, USA. Chloe Brown is an employee of Merck Sharp \& Dohme, Hoddesdon, UK. Eilish McCann is an employee of Merck Sharp \& Dohme, Hoddesdon, UK.

Compliance with Ethics Guidelines. This article is a modeling study using data derived from previously conducted studies, and does not contain any new studies with human or animal subjects performed by any of the authors.

Data Availability. The datasets generated during and/or analyzed during the current study are available from the corresponding author on reasonable request.

Open Access. This article is distributed under the terms of the Creative Commons Attribution-NonCommercial 4.0 International License (http://creativecommons.org/licenses/ by-nc/4.0/), which permits any noncommercial use, distribution, and reproduction in any medium, provided you give appropriate credit to the original author(s) and the source, provide a link to the Creative Commons license, and indicate if changes were made.

\section{REFERENCES}

1. Sieper J, Rudwaleit M, Baraliakos X, et al. The Assessment of SpondyloArthritis international Society (ASAS) handbook: a guide to assess spondyloarthritis. Ann Rheum Dis. 2009;68(Suppl 2):ii1-44.

2. Rudwaleit M, van der Heijde D, Khan MA, Braun J, Sieper J. How to diagnose axial spondyloarthritis early. Ann Rheum Dis. 2004;63(5):535-43.

3. Rudwaleit M, van der Heijde $D$, Landewe R, Listing J, Akkoc N, Brandt J, et al. The development of Assessment of Spondyloarthritis International Society classification criteria for axial spondyloarthritis (part II): validation and final selection. Ann Rheum Dis. 2009;68(6):777-83.

4. Sieper J, van der Heijde D. Review: nonradiographic axial spondyloarthritis: new definition of an old disease? Arthritis Rheum. 2013;65:543-51.

5. Sieper J, Hu X, Black CM, et al. Systematic review of clinical, humanistic, and economic outcome comparisons between radiographic and non-radiographic axial spondyloarthritis. Semin Arthritis Rheum. 2017;46:746-53.

6. Deodhar A, Strand V, Kay J, et al. The term 'nonradiographic axial spondyloarthritis' is much more important to classify than to diagnose patients with axial spondyloarthritis. Ann Rheum Dis. 2016;75:791-4.

7. Rudwaleit M, Haibel H, Baraliakos X, et al. The early disease stage in axial spondylarthritis: results from the German Spondyloarthritis Inception Cohort. Arth Rheum. 2009;60:717-27.

8. Poddubnyy D, Haibel H, Braun J, et al. Patients with non-radiographic axial spondyloarthritis and ankylosing spondylitis demonstrate the same clinical disease course over two years: results from the GESPIC cohort. Ann Rheum Dis. 2014;73(Suppl 2):THU0071 (abstract).

9. Poddubnyy D, Brandt H, Vahldiek J, et al. The frequency of non-radiographic axial spondyloarthritis in relation to symptom duration in patients referred because of chronic back pain: results from the Berlin early spondyloarthritis clinic. Ann Rheum Dis. 2012;71:1998-2001.

10. Kiltz U, Baraliakos X, Karakostas P, et al. Do patients with non-radiographic axial spondylarthritis differ from patients with ankylosing spondylitis? Arthritis Care Res. 2012;64:1415-22.

11. Akgol G, Kamanli A, Ozgocmen S. Evidence for inflammation-induced bone loss in non- 
radiographic axial spondyloarthritis. Rheumatology. 2014;53:497-501.

12. Osterhaus JT, Purcaru O. Discriminant validity, responsiveness and reliability of the arthritis-specific Work Productivity Survey assessing workplace and household productivity within and outside the home in patients with axial spondyloarthritis, including nonradiographic axial spondyloarthritis and ankylosing spondylitis. Arthritis Res Ther. 2014;16:R164-79.

13. Van der Heijde D, Purcaru O, Kavanaugh A. High economic burden of axial spondyloarthritis related to paid work and household productivity at baseline in the rapid-axspa study: differences and similarities between ankylosing spondylitis and nonradiographic axial spondyloarthritis (FRI0439). Ann Rheum Dis. 2013;72(Suppl 3):523.

14. Harvard S, Guh G, Bansback N, Richette P, Douga$\operatorname{dos}$ M, Anis A, Fautrel B. Costs of early spondyloarthritis: estimates from the first 3 years of the DESIR cohort. RMD Open. 2016;2:e00230.

15. Braun J, van den Berg R, Baraliakos X, et al. 2010 update of the ASAS-EULAR recommendations for the management of ankylosing spondylitis. Ann Rheum Dis. 2011;70:896-904.

16. Humira Pre-filled Pen, Pre-filled Syringe and Vial. Summary of Product Characteristics. Available at: http://www.medicines.org.uk/emc/medicine/ 21201.

17. Cimzia $200 \mathrm{mg}$ solution for injection. Summary of Product Characteristics. Available at: http://www. medicines.org.uk/emc/medicine/22323.

18. Sieper J, Van der Heijde D, Dougados M, et al. A randomized, double-blind, placebo-controlled, sixteen-week study of subcutaneous golimumab in patients with active nonradiographic axial spondyloarthritis. Arthritis Rheumatol. 2015;67:2702-12.

19. Garrett S, Jenkinson T, Kennedy LG, Whitelock H, Gaisford P, Calin A. A new approach to defining disease status in ankylosing spondylitis: the Bath Ankylosing Spondylitis Disease Activity Index. J Rheumatol. 1994;21:2286-91.

20. Anderson JJ, Baron G, van der Heijde D, Felson DT, Dougados M. Ankylosing spondylitis assessment group preliminary definition of short-term improvement in ankylosing spondylitis. Arthritis Rheum. 2001;44:1876-86.

21. Bakland G, Gran JT, Nossent JC. Increased mortality in ankylosing spondylitis is related to disease activity. Ann Rheum Dis. 2011;70:1921-5.
22. Haibel H. Efficacy of adalimumab in the treatment of axial spondylarthritis without radiographically defined sacroiliitis: results of a twelve-week randomized, double-blind, placebo-controlled trial followed by an open-label extension up to week fifty-two. Arthritis Rheum. 2008;7:1981-91.

23. Sieper J. Efficacy and safety of adalimumab in patients with non-radiographic axial spondyloarthritis: results of a randomised placebo-controlled trial (ABILITY-1). Ann Rheum Dis. 2012;6:815-22.

24. Landewe R. Efficacy of certolizumab pegol on signs and symptoms of axial spondyloarthritis including ankylosing spondylitis: 24-week results of a doubleblind randomised placebo-controlled phase 3 study. Ann Rheum Dis. 2014;1:39-47.

25. Maksymowych WP, Van Der HD, Dougados $M$, Sieper J, Braun J, Citera G, et al. Clinical and imaging efficacy of etanercept in early non-radiographic axial spondyloarthritis: 48-week treatment data. Ann Rheum Dis. 2014; Conference (var.pagings): June.

26. Dougados $M$, Van Der HD, Sieper J, Braun J, Maksymowych WP, Citera G, et al. Clinical and imaging efficacy of etanercept in early non-radiographic axial spondyloarthritis: a 12-week, randomized, double-blind, placebo-controlled trial. Ann Rheum Dis. 2013; Conference(var.pagings):June.

27. McLeod C, Bagust A, Boland A, et al. Adalimumab, etanercept and infliximab for the treatment of ankylosing spondylitis: a systematic review and economic evaluation. Health Technol Assess. 2007;11:1-158, iii-iv.

28. British National Formulary August 2015. Available at: https://www.medicinescomplete.com/mc/bnf/ current/.

29. Simponi $50 \mathrm{mg}$ solution for injection. Summary of Product Characteristics. Available at: http://www. medicines.org.uk/emc/medicine/23766.

30. Enbrel $50 \mathrm{mg}$ solution for injection in pre-filled pen. Summary of Product Characteristics. Available at: http://www.medicines.org.uk/emc/medicine/ 22143.

31. Personal Social Services Research Unit. 2014. Available at: http://www.pssru.ac.uk/.

32. National Institute for Health and Excellence. Technology Appraisal Guidance. TNF-alpha inhibitors for ankylosing spondylitis and non-radiographic axial spondyloarthritis. https://www.nice. org.uk/guidance/ta383/. 
33. Personal Social Services Research Unit. Unit Costs of Health and Social Care 2014. http://www.pssru. ac.uk/project-pages/unit-costs/2014/.

34. Boonen A, van der Heijde D, Landewé R, Guillemin F, Rutten-van Mölken M, Dougados M, et al. Direct costs of ankylosing spondylitis and its determinants: an analysis among three European countries. Ann Rheum Dis. 2003;62:732-40.

35. National Institute for Health and Excellence. TNFalpha inhibitors for ankylosing spondylitis and axial spondyloarthritis without radiographic evidence of ankylosing spondylitis (including a review of technology appraisal 143 and technology appraisal 233) Assessment Report. https://www. nice.org.uk/guidance/ta383/documents/ ankylosing-spondylitis-and-axial-spondyloarthritisnonradiographic-adalimumab-etanerceptinfliximab-and-golimumab-inc-rev-ta143-andta233-id694-appraisal-consultation-document2.

36. Briggs A, Claxton K, Sculpher M. Decision modelling for health economic evaluation. Oxford University Press, 2006.

37. Exarchou S, Lie E, Lindström U, Askling J, Forsbladd'Elia H, Turesson C, Kristensen LE, Jacobsson LT. Mortality in ankylosing spondylitis: results from a nationwide population-based study. Ann Rheum Dis. 2016;75:1466-72.

38. Bansback N, Maetzel A, Drummond M, et al. Considerations and preliminary proposals for defining a reference case for economic evaluations in ankylosing spondylitis. J Rheumatol. 2007;34(5):1178-83.

39. Ankylosing spondylitis and axial spondyloarthritis (non-radiographic)_adalimumab, etanercept infliximab and golimumab (inc rev TA143 and TA233) ID694. NICE. http://www.nice.org.uk/ guidance/indevelopment/gid-tag355.

40. Kobelt G, Andlin-Sobocki P, Brophy S, Jönsson L, Calin A, Braun J. The burden of ankylosing spondylitis and the cost-effectiveness of treatment with infliximab (Remicade). Rheumatology (Oxford). 2004;43:1158-66.

41. Singh JA, Wells GA, Christensen R, Tanjong Ghogomu E, Maxwell L, Macdonald JK et al. Adverse effects of biologics: a network meta-analysis and Cochrane overview. Cochrane Database Syst Rev. 201116;2:CD008794. https://doi.org/10.1002/ 14651858.cd008794.pub2. 